\title{
ANALISIS KADAR MERKURI PADA KRIM PEMUTIH YANG DI PERJUAL BELIKAN SECARA ONLINE DI KOTA MAKASSAR
}

\author{
Nuradi \\ Jurusan Analis Kesehatan Poltekkes Kemenkes Makassar \\ Koresponden : nuradi.poltekkes.mks@gmail.com
}

\begin{abstract}
ABSTRAK
Latar belakang penelitian ini adalah merkuri merupakan salah satu bahan berbahaya yang terkadang masih di temukan di dalam kandungan sebuah Krim pemutih. Tujuan penelitian untuk mengetahui ada tidaknya merkuri dan menentukan kadar merkuri pada krim pemutih yang dipejual belikan secara online. Penelitian ini bersifat destriptif dan dilaksanakan di Balai besar laboratorium kesehatan Makassar pada tanggal 4 agustus - 11 agustus 2016 dengan jumlah sampel 7 yang di beli di berbagai toko online di kota makassar secara Accidental sampling. Hasil penelitian ditemukan adanya logam merkuri (Hg) dengan jumlah kadar 0,1429-1531.5713 ug/g. Berdasarkan keputusan BPOM No. HK. 03. 1.23.08.11.07517 tahun 2011 bahwa raksa dilarang digunakan dalam kosmetik maka Krim Pemutih yang beredar yang di perjual belikan secara online di Kota Makassar tersebut tidak memenuhi persyaratan yang telah di tetapkan.Disarankan kepada peneliti selanjutnya untuk meneliti logam berat lainnya pada krim pemutih yang beredar di pasar.

Kata kunci : Merkuri, Spektrofotometri Serapan Atom, Krim Pemutih

\section{PENDAHULUAN}

Kosmetik bukan sesuatu yang baru. kosmetik telah di kenal sejak dahulu dan merupakan unsur kebudayaan masyarakat sepanjang masa perkembangan umat manusia. sebab kecantikan dan kesehatan lahir batin merupakan vitalitas hidup yang harus dimilki oleh setiap orang, baik wanita maupun pria, penilaian bentuk rupa serta norma-norma kecantikan sesuai dengan tuntunan zaman dan di pengaruhi oleh lajunya ilmu pengetahuan, pertumbuhan teknologi serta perkembangan jenis-jenis kosmetik ( Anonim 2013).

Di era teknologi serba canggih saat ini segala hal yangt menjadi lebih

praktis dan mudah, tidak terkecuali dalam hal kosmetik dan produk kecantikan, dimana saat ini, tersedia berbagai produk kecantikan yang secara instan dapat menjadikan wanita terlihat cantik. Mereka yang merasa kurang percaya diri karena memiliki warna kulit yang gelap, akhirnya mereka pun berburu produk pemutih kulit tanpa terlebih dahulu menghiraukan kandungan yang terdapat di dalam produk tersebut. mereka berfikir untuk menggunakan jalan instan saja, yang penting kulit mereka terlihat putih bahkan karena harga produk-produk kecantikan yang mengandung bahan kimia berbahaya sering kali mempunyai harga yang jauh lebih murah di banding produk
\end{abstract}


berbahan alami salah satu yang banyak dicari adalah krim pemutih. (Anonim,2013)

Krim pemutih yang mengandung $\mathrm{Hg}$ (Merkuri) tidak aman digunakan karena merkuri dan senyawanya termaksud dalam daftar kosmetik yang dilarang sesuai lampiran 1 peraturan Kepala Badan POM No.HK.00.05..42.1018 tahun 2008 tentang bahan kosmetik, dinyatakan bahwa merkuri dan senyawanya termaksud dalam daftar yang dilarang kecuali merkuri dalam senyawa yang tercantum dalam lampiran IV daftar bahan pengawet yang diisinkan digunakan dalam kosmetik, Garam fenil merkuri dan Thio mersal(NN) dengan kadar maksimun 0,007\% ( dihitung sebagai $\mathrm{Hg}$ ) Jika dicampur dengan senyawa merkuri lain yang diijinkan, maka konsentrasi maksimun $\mathrm{Hg}$ tetap $0,007 \%$, dengan batasan hanya digunakan sebagai pengawet untuk sediaan tata rias mata dan pembersih tata rias mata dan mencantumkan peringatan penandaan/ kemasan ( mengandung senyawa fenil merkuri) dan ( mengandung thio mersal).(Slamet riyaldi, 2011).

Pemakaian Merkuri dalam krim pemutih dapat menimbulkan berbagai hal, mulai dari perubahan warna kulit yang pada akhirnya dapat menyebabkan bintik-bintik hitam pada kulit, alergi, iritasi kulit serta pemakaian dengan dosis tinggi dapat menyebabkan kerusakan permanen otak, serta dapat menyebabkan kanker. Meluasnya dagangan kosmetik pemutih wajah ilegal ini juga didukung oleh faktor produsen yang semakin lama semakin banyak. Sekarang sudah tercatat 9 online shop yang menjual kosmetik tidak bermerek secara online di Kota Makassar. Tidak hanya itu, mereka sudah berani menyediakan stok kosmetik-kosmetik tidak bermerek ini dirumah mereka. Hal ini tentunya lebih mempermudah konsumen untuk mendapatkan kosmetik tidak bermerek tersebut. Selain itu, faktor lain yang mendukung beredarnya kosmetik-kosmetik yang diduga berbahaya ini dikarenakan persepsi masyarakat tentang perawatan. (Santoso,2012)

Kepala Badan Pengawas Obat Dan Makanan (BPOM) RI. Lucky S.Slamet mengumumkan 17 kosmetik yang mengandung bahan berbahaya. Ke 17 produk ini beredar tanpa izin BPOM dan mengandung merkuri, hydrokinon, asam retinoat dan resorsinor, selain itu dijual di toko kosmetik beberapa produk dijual di klinik kecantikan dan toko online. (Firmansyah,2013)

Berdasarkan peraturan kepala Badan Pegawasan Obat dan Makanan (BPOM) nomor HK.03.1.23.08.11.07517 tahun 2011 tentang Pegawasan Obat dan Makanan (BPOM) nomor HK.03.1.23.08.11.07517 tahun 2011 tentang persyaratan teknik bahan kosmetik, melarang penggunaan merkuri pada kosmetik. Merkuri $(\mathrm{Hg})$ /Air Raksa termaksuk logam berat berbahaya yang dalam konsentrasinya kecilpun dapat bersifat racun. Pemakaian merkuri dalam kosmetik dapat menimbulkan berbagai hal, mulai dari perubahan warna kulit yang pada akhirnya dapat menyebabkan bintik-bintik hitam pada kulit, alergi 
iritasi kulit serta pemakaian dengan dosis tinggi dapat menyebabkan kerusakan permanen otak, ginjal dan gangguan perkembangan janin bahkan paparan jangka pendek dalam dosis tinggi juga dapat menyebabkan kanker pada manusia. Tujuan Penelitian adalah untuk mengetahui ada tidaknya merkuri pada berbagai krim pemutih yang di perjual belikan secara online di Kota Makassar. Untuk menentukan kadar merkuri pada berbagai krim pemutih yang di perjualbelikan secara online di Kota Makassar.

\section{METODE}

\section{Jenis, Tempat dan Waktu Penelitian} Jenis penelitian ini adalah observasi laboratorik yang bersifat deskriptif yang bertujuan untuk mengetahui kadar merkuri $(\mathrm{Hg})$ pada krim pemutih yang diperjual belikan secara online di Kota Makassar. Tempat penelitian dilaksanakan di Balai Besar Laboratorium Kesehatan Makassar. Waktu Penelitian dilaksanakan pada bulan Agustus 2016

\section{Populasi, Sampel, Teknik Pengambilan Sampel, Alat dan Bahan}

Populasi dalam penelitian ini adalah krim pemutih yang diperjual belikan secara online di Kota Makassar. Sampel dalam penelitian ini adalah krim pemutih yang diambil di setiap penjual online krim pemutih di Kota Makassar. Besar sampel dalam penelitian ini adalah $7 \mathrm{krim}$ pemutih yang diambil di setiap penjual online di Kota Makassar. Teknik pengambilan sampel dalam penelitian ini adalah secara Accidental Sampling.
Alat yang digunakan dalam penelitian ini adalah : Neraca analitik, Petridish, Spatula / Sendok tanduk, Batang pengaduk, Labu semprot, Tabung reaksi, Rak tabung, Pipet tetes, Oven, Pipet volume $1 \mathrm{ml}, 2 \mathrm{ml}, 5 \mathrm{ml}$, $10 \mathrm{ml}$ dan 20ml, Gelas piala, Corong, Standar corong, Labu ukur, Tabung nessler, Bulf (karet Pengisap), Pipet skala, Spektrofotometer serapan atom (AAS) dilengkapi dengan alat bantu unit penguap (MVU-1A) sedangkan bahan yang digunakan dalam penelitian ini adalah : Krim pemutih, Merkuri (II) klorida, Kalium permanganat (KmnO4) 5\%, Larutan SnCL2 $10 \%$ dalam asam klorida 3\%, Asam nitrat 65\%, Asam sulfat 95\% 97\%, Hydroxylamine HCL 5\%, Kalium peroksodisulfat K2S2O8) $10 \%$, Asam sulfat $10 \mathrm{~N}$, Aquadest, Natrium hidroksida $(\mathrm{NaOH}) 0,1 \mathrm{~N}$, Kalium iodida (KI) $10 \%$, Larutan amoniak.

\section{Prosedur Penelitian}

Pengambilan sampel:

Sampel berupa 7 buah krim pemutih kosmetika dengan merk yang berbeda ditempatkan dalam wadah.

Pembuatan larutan standar merkuri (Hg).

Larutan standar primer merkuri 1000 ppm. Sebanyak 0,1354 g raksa (II) klorida ditimbang. Dilarutkan dengan $75 \mathrm{~mL}$ aquadest dan $1 \mathrm{~mL}$ asam nitrat pekat, kemudian volumenya dicukupkan dengan aquadest hingga $100 \mathrm{~mL}$. Larutan standar sekunder pertama: 10 ppm Sebanyak $1 \mathrm{~mL}$ larutan primer merkuri 1000 ppm dipipet ke dalam labu ukur $100 \mathrm{~mL}$, lalu volumenya dicukupkan hingga $100 \mathrm{~mL}$ dengan aquadest. 
Larutan standar merkuri kedua : 1 ppm Sebanyak $5 \mathrm{~mL}$ larutan standar merkuri 10 ppm dipipet ke dalam labu ukur $50 \mathrm{~mL}$, lalu volumenya dicukupkan hingga $50 \mathrm{~mL}$ dengan aquadest. Larutan standar merkuri ketiga : $100 \mathrm{ppb}$ Sebanyak $10 \mathrm{~mL}$ larutan standar merkuri 1 ppm dipipet ke dalam labu ukur $100 \mathrm{~mL}$, lalu volumenya dicukupkan hingga 100 $\mathrm{mL}$ dengan aquadest. Larutan standar kerja (10 ppb, $20 \mathrm{ppb}, 30 \mathrm{ppb}, 40 \mathrm{ppb}$ dan $50 \mathrm{ppb}$ ) Dipipet 10ml, 20ml, 30ml, $40 \mathrm{ml}$, dam $50 \mathrm{ml}$ dari larutan standar merkuri 100 ppb dimasukkan kedalam labu ukur $100 \mathrm{ml}$ lalu volumenya dicukupkan hingga $100 \mathrm{~mL}$ dengan aquadest. (larutan standar kerja dibuat ketika akan melakukan analisa).

Pembuatan Larutan sampel:

Ekstraksi dari sediaan Krim, Kedalam corong pisah masukkan $2 \mathrm{~g}$ sampel, $75 \mathrm{ml}$ eter kocok sampai dasar krim larut $+10 \mathrm{ml}$ HCL 1:10 dikocok keras Fase air dipisahkan dan disaring dengan kertas saring. Fase eter dicuci 2x dengan HCL 1:10. Setiap fase air dan air pencuci dikumpulkan ke dalam labu takar $50 \mathrm{ml}$ dan ditambahkan aquadest sampai tanda

Analisa logam merkuri secara kualitatif

Prinsip: Pemeriksaan secara kualitatif dalam krim pemutih adalah pemeriksaan pendahuluan yang dilakukan untuk mengetahui ada tidaknya logam dalam sampel krim pemutih yang diperiksa yang dilakukan dengan cara didigestion dan dilanjutkan dengan reaksi pengendapan.

Cara kerja:

Larutan sampel ditambahkan natrium hidroksida encer, hasil positif bila terbentuk endapan warna hitam. Larutan contoh ditambahkan Kalium iodida perlahan-lahan, hasil positif bila terbentuk endapan merah. Larutan sampel ditambahkan amoniak, hasil positif bila terbentuk endapan putih.

Analisa logam merkuri secara kuantitatif

Analisa ini menggunakan Spektrofotometer Serapan Atom tanpa nyala. Dilakukan pengukuran absorbance blanko, standar dan sampel pada panjang gelombang $253,7 \mathrm{~nm}$.

Analisa Data

Data yang diperoleh dari hasil pemeriksaan disajikan secara dekskriptif dalam bentuk tabel dan hasilnya dibahas dalam bentuk narasi.

\section{HASIL}

Berdasarkan hasil pemeriksaan analisis kadar merkuri pada krim pemutih yang di perjual belikan secara online di Kota Makassar, yang dilakukan pada tanggal 4-11 Agustus 2016 di Balai Besar Laboratorium Kesehatan makassar dengan metode analisis secara kualitatif dan kuantitatif. Maka diperoleh hasil pemeriksaan tabel sebagai berikut: 
Tabel 1 .

Hasil pemeriksaan kadar merkuri pada krim pemutih yang di perjual belikan secara online di Kota Makassar.

\begin{tabular}{ccccc}
\hline No & No.Lab & Kode Sampel & Satuan & Raksa (Hg) \\
\hline 1 & 16112498 & A & $\mathrm{Ug} / \mathrm{g}$ & 0.1429 \\
2 & 16112499 & $\mathrm{~B}$ & $\mathrm{Ug} / \mathrm{g}$ & 62.0360 \\
3 & 16112500 & $\mathrm{C}$ & $\mathrm{Ug} / \mathrm{g}$ & 373.7867 \\
4 & 16112501 & $\mathrm{D}$ & $\mathrm{Ug} / \mathrm{g}$ & 0.0492 \\
5 & 16112502 & $\mathrm{E}$ & $\mathrm{Ug} / \mathrm{g}$ & 1531.5713 \\
6 & 16112503 & $\mathrm{~F}$ & $\mathrm{Ug} / \mathrm{g}$ & 3.2678 \\
7 & 16112504 & $\mathrm{G}$ & $\mathrm{Ug} / \mathrm{g}$ & 1322.3880 \\
\hline
\end{tabular}

\section{PEMBAHASAN}

Merkuri adalah logam berat berbentuk cair, berwarna putih perak, serta mudah menguap pada suhu ruangan. Merkuri akan memadat pada tekanan 7.640 Atm. Merkuri dapat larut dalam asam sulfat atau asam nitrit, tetapi tahan terhadap basa. Merkuri memiliki nomor atom 80 . Berat atom 200,59 g/mol, titik lebur $38,9^{\circ} \mathrm{C}$, dan titik didih $356,6^{\circ} \mathrm{C}$. Merkuri merupakan salah satu unsur kimia yang biasa digunakan pada proses pemisahan emas dengan unsur logam ikatan lainnya. Merkuri termaksud logam bersifat toksik (Racun). Merkuri merupakan logam yang dalam keadaan normal berbentuk cairan warna abu-abu tidak berbaun dengan molekul 200,59. tidak larut dengan air, alkohol, eter, asam hidroclorida.

Kosmetik adalah bahan atau campuran bahan untuk digosokkan diletakkan, dituangkan, dipercikkan, atau disemprotkan pada, dimasukkan dalam, dipergunakan pada badan atau bagian badan manusia dengan maksud untuk membersihkan, memelihara, menambah daya tarik atau mengubah rupa dan tidak termasuk golongan obat (Nelly Hakim, 1999 : 15).

Analisis merkuri pada krim pemutih yang diperjual belikan secara online di Kota Makassar sampel menggunakan A,B,C,D,E,F,G dilakukan uji warna sebagai analisis kualitatif dan analisis kuantitatif dengan metode spektrofotometri serapan. Pada analisis kualitatif hasil positif menunjukkan warna merah orange sedangkan metode spektrofotometri digunakan untuk mengukur absorban suatu sampel.

Hasil penelitian uji kualitatif dengan menambahkan Natrium Acid $65 \% 10 \mathrm{ml}$ dengan hasil positif dari sampel A,B,C,D,E,F,G yang ditandai dengan perubahan warna menjadi merah orange. Untuk membuktikan secara jelas, maka ketujuh sampel tersebut dianalisis menggunakan spektrofotometer dengan panjang gelombang 253,7nm. Sampel yang berisi $100 \mathrm{ml}$ masukkan kedalam botol penyerap merkuri ditambahkan Asam sulfat $10 \mathrm{~N}$ sebanyak $10 \mathrm{ml}$ kemudian masukkan batang pengaduk magnetic, tambahkan 5ml larutan $\mathrm{SnCl} 2$ 
diamkan selama 2 menit, kemuadian baca uap merkuri dengan menggunakan spektrofotometer. hasil pemeriksaan menggunakan spektrofotometer menunjukkan bahwa dari 7 sampel krim pemutih yang diperjual belikan secara online di Kota Makassar positif mengandung merkuri. Pada sampel A mengandung kadar merkuri sebanyak $0.1429 \mathrm{Ug} / \mathrm{g}$ (0,001429\%), sampel B $62.0360 \mathrm{Ug} / \mathrm{g}$ (0,062036\%), sampel C 373.7867 $\mathrm{Ug} / \mathrm{g}(0,3737867 \%)$, sampel D 0.0492 $\mathrm{Ug} / \mathrm{g}(0,00492)$, sampel E 1531.5713 $\mathrm{Ug} / \mathrm{g}(1,5315713 \%)$, sampel F 3.2678 $\mathrm{Ug} / \mathrm{g} \quad(0,0032678 \%)$, sampel G $1322.3880 \mathrm{Ug} / \mathrm{g}(1,322388 \%)$.

Sampel krim pemutih yang mengandung merkuri yang melebihi kadar ketentuan dari POM beredar luas diperjual belikan secara online.Sampel krim pemutih yang mengandung merkuri merupakan sampel yang diperjual belikan secara online, Hal ini seharusnya diperhatikan oleh pemerintah karna ketujuh sampel krim pemutih yang mengandung merkuri sudah sangat jelas tidak memiliki nomor POM dan tidak memiliki komposisi pada kemasan. Krim pemutih banyak digunakan masyarakat khususnya bagi kaum wanita sangat membahayakan kesehatan, Pemakaian Merkuri dalam krim pemutih dapat menimbulkan berbagai hal, mulai dari perubahan warna kulit yang pada akhirnya dapat menyebabkan bintik-bintik hitam pada kulit, alergi, iritasi kulit serta pemakaian dengan dosis tinggi dapat menyebabkan kerusakan permanen otak, serta dapat menyebabkan kanker.

\section{KESIMPULAN}

Berdasarkan hasil penelitian, maka dapat disimpulkan bahwa 7 sampel krim pemutih yang diperjual belikan secara online di Kota Makassar menggandung Merkuri ( $\mathrm{Hg}$.

\section{SARAN}

1. Diharapkan kepada produsen dalam memilih produk kosmetik agar sekiranya memperhatikan manfaat dan dampak buruk serta kandungan bahan kimia yang merugikan kesehatan dan menggunakan bahan kosmetik yang memiliki nomor POM.

2. Diharapkan kepada instansi pemerintah yang terkait untuk melakukan pengawasan pada penjualan online produk kosmetik krim pemutih secara online.

3. Disarankan kepada peneliti selanjutnya untuk menganalisis kadar merkuri pada sabun pemutih wajah, lipstik, dan body lotion yang beredar di pasaran.

\section{DAFTAR PUSTAKA}

Arvitasari Nila, 2015, Analisis merkuri (Hg) pada handbody yang dijual dipasar tradisional kota makassar,Poltekkes kemenkes makassar jurusan analis kesehatan.

Anonim. 2007 www.mediakonsumen.com, diakses tanggal 8 juni 2016

Anatonim. 2013 Bahaya Pemutih Yang Mengandung Merkuri (online). http://www. venamele.com/body-andmind/cantik/1957-bahaya-krim- 
pemutih yang-mengandungmerkuri. diakses tanggal 8 juni 2016

Ahmad, A.K. Muda. 2006. Kamus lengkap bahasa indonesia. Jakarta : Realiti publiser

Badan Pegawasan Obat Dan Makanan (BPOM). 2009 puplik warning/peringatan. Jakarta

Dekrit, 2013, Analisis merkuri pada kerang hijau (mytilus viridis) yang diperjual belikan dipasar lelong rajawali makassar, Universitas indonesia timur.

Frank, C. LU. 1995. Toksiologi Dasar edisi II. Jakarta : Ui press

Firmansyah. 2013. Daftar Kosmetik yang mengandung merkuri, www.carpedia.com, Diakses tanggal 11 juni 2016

Nelly Hakim. 1999. Tata kecantikan kulit tingkat terampil. Jakarta : Mulia mulya citra sarana

Sartono, 2012 Racun Dan Keracunan. Jakarta : Wijaya medika

Slamet riyadi. 2011. Analisi kadar merkuri didalam krim pemutih dengan menggunakan alat analisa gengem niton XL3t GOLDD+ : http://www .tawadascientivic.com (28 Juni 2016)

Traggono, R, I., Fatma, I.2007. Buku pegangan ilmu pengetahuan Kosmetik. Jakarta PT. Gramedia Pustaka Utama.

Widowati dkk 2008 Arti, definisi, pengertian, info/ sifat-sifat merkuri 